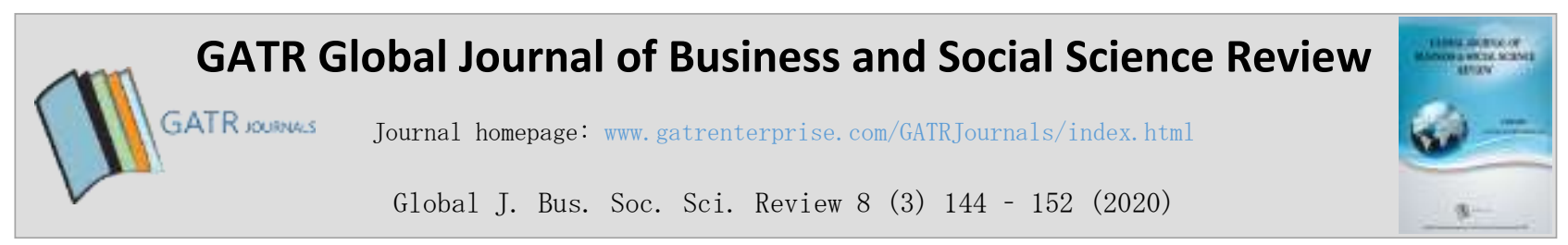

\title{
Endeavours: The Relationship in Social Network of Thai Student Labourers in Australia
}

\author{
Thanapauge Chamaratana \\ Assistant Professor, Department of Social Sciences, Faculty of Humanities and Social Sciences, \\ Khon Kaen University, 40002, Thailand
}

\begin{abstract}
Objective - This article aims to examine the relationship in the social network of Thai student labourers or special migrants known as "Thai-Aus labourers", who are studying and working in Sydney, Australia.

Methodology/Technique - Data was collected via in-depth interviews with 18 key Thai-Aus labourers in Sydney, Australia. These key informants were selected using the snowball technique. Content analysis was performed with the data based on the ATLAS.ti programme, and the social networks were analysed using the Ucinet and Netdraw programme.

Finding - The results conclude that the relationships within the social networks of the Thai-Aus labourers were complex, although they each shared the same goal. The relationships were principally based on benefit exchange even though personal relationships appeared on the surface.

Novelty - The directional flow in the pattern of benefit-giving and receiving, and the duration, did not affect relationships, which depended more on personal cases.
\end{abstract}

Type of Paper: Empirical.

JEL Classification: J21, J29.

Keywords: Brokers; Social Network; Migrant Labour Network; Working Abroad of Thai Labourers.

Reference to this paper should be made as follows: Chamaratana, T. (2020). Endeavours: The Relationship in Social Network of Thai Student Labourers in Australia, Global J. Bus. Soc. Sci. Review, 8(3): $144 \quad-152$. https://doi.org/10.35609/gjbssr.2020.8.3(1)

\section{Introduction}

Migration among Thai nationals to take advantage of opportunities to study abroad has been ever increasing over the last 3 decades. This is reflected in the number of laborers migrating abroad and the number of job seekers already registered to work abroad under the Ministry of Labour's regulation, accounting for hundreds of thousands migrants each year.

\footnotetext{
${ }^{*}$ Paper Info: Revised: June 10, 2020

Accepted: September 30, 2020

* Corresponding author: Thanapauge Chamaratana

E-mail: thanacha@kku.ac.th

Affiliation: Assistant Professor, Department of Social Sciences, Faculty of Humanities and Social Sciences,

Khon Kaen University, Thailand.
} 
The legal migration of Thai labourers can be classified into 5 groups, namely: by an employment company, by the Department of Employment, by the job seekers themselves, by their Thai employer who takes them abroad, and by their Thai employer who takes their employees abroad as a novice (Chamaratana et. al., 2010).

However, in the course of the migration process, concealed migration innovations of various patterns have emerged such as entering into marriage with a national of the destination country to enable them to make a claim for a migration visa, work and travel, and development of students' traditional migration to work by doing part-time jobs. The latter group of migrants has given rise to vast opportunities for businesses to send educated and middle-class people and new labourers with a desire for new experiences abroad to work in developed countries where higher education institutions are available to them. These migrants are enrolled into an academic institute and use their rights to work part-time before eventually becoming full-time labourers.

In Australia, Thai migrants are very common and have been colloquially dubbed 'Thai-Aus Labourers' referring to Thai students who have entered Australia by enrolling into an academic institute and thereby gaining rights to work part-time during their studies. They commonly take low-end jobs such as cleaners, dish washers, or kitchen cleaners. Many students leave their education and work full-time to save money and send money back home for payment of their education costs. In this way, many of the Thai-Aus labourers risk contravening the terms of their student visas. Moreover, they are not entitled to any fringe benefits or labour protection whilst they are in the workforce. The law protecting Thai labourers working abroad of the Ministry of Labour does not cover such cases (Office of Thai Labour Administration, 2017) since their status is not a "migrant labourer" but as a "student".

It has been found that student labourers in Australia or Thai-Aus Labourers have a key strategy to eliminate this problem, i.e., using their social network among the friend groups that chat on line and via the Cyber Space to assist one another. This forms the basis of the research question in this study, whicb is "How are Thai student labourers in Australia able to live abroad?"

In order to answer this question, the author had an intention to study the relationship in the social network of Thai student labourers in Australia based on the concept of Boissevain (1974) and developed a conceptual framework for social network analyses, which were divided into 4 dimensions as follows:

1. the roles of various social network members

2. the basis of the relationships within the social network, usually based on the exchange theory

3. the consideration of directional flow of relationships

4. the frequency and duration of relationships within the social network

\section{Research Methodology}

A Qualitative Method was applied in this research, with the unit of analysis being the individual level as Thai student labourers in order to consider the relationships within the social network. The key informants in this study comprised 18 Thai student labourers in Australia or Thai-Aus labourers selected using the Snowball Technique. The following 3 criteria were used in the selection process:

1. the informant was a Thai student labourer entering Australia on a student visa;

2. the informant was a Thai student labourer who had studied and worked in Australia for at least 3 months at the interview time; and

3. the informant was a Thai student labourer who had not been granted an Australian citizenship.

The selection was based on the Snowball Technique because that technique is appropriate for studies focusing on social networks. It enables the researchers to directly visualize the relationships and connections within the social network of the Thai-Aus labourers. Moreover, it assists the researchers to verify the data

Global J. Bus. Soc. Sci. Review 8 (3) 144 -152 (2020) 
given by each of the individual key informants. In addition, the Snowball Technique is by its nature suitable for a social network analysis (SNA) (Wasserman \& Faust, 1999; De Jong, 2008; Ayuwat \& Chamaratana, 2013).

The in-depth interview technique was used to collect the data. This involved interviewing the Thai-Aus labourers one by one based on the interview guidelines which were used as the data collection tool. The indepth interview was performed by the researchers using the following steps:

1. Contacting the target group prior to the data collection date via online communication network such as Facebook Messenger, Line free calls, We Chat, or Skype programme.

2. Coordination via Facebook social network to make a request to collect data from the Thai-Aus labourers and to make an appointment for the interview.

3. The data collection period was from March 2015 until May 2016, totaling a period of 15 months.

4. The researchers went to Australia on July 24-26, 2015 to interview the key informants who were the center of the social networks.

The validity and reliability of the qualitative data was triangulated using the Data Source Triangulation Technique (Creswell \& Clark, 2007; Srisantisuk, 2007). The data from the in-depth interviews was physically ordered through transcribing and editing the field notes, typed on the computer using Microsoft Word, and assigned in the ATLAS.ti programme. Content analysis was performed to categorise, interpret, compare, find correlate and identify patterns for inductive conclusion (Srisantisuk, 2007). This conclusion comprises the background, job characteristics, and all that are related to Thai-Aus labourers' social networks, especially the brokers' roles in these networks. Finally, Social Network Analysis was used to analyse the relationships within the Thai-Aus labourers' social networks, using the UCINet programme. The data analysis as conducted by first pairing the relationship of each key informant before using the programme to demonstrate the results of the relationship. The outcome of the social network model is illustrated using the Netdraw programme (De Nooy, Batagelj, \& Mrvar, 2005).

In order to follow the research framework of ethics, the names of Thai-Aus labourers are represented by pseudonyms.

\section{The Social Network of Thai-Aus Labourers}

The social networks forming the knit and ties of individuals that form into different group patterns were on the bases of perception and decision for exchanges. Relationships among people in society reflect social network intensity. In other words, if an individual is known by many people or has relationships with a lot of people, that person has a dense social network. On the contrary, an individual known by few people has a loose social network (Wasserman \& Faust, 1999). Likewise, the informal social network pattern of Thai-Aus Labourers was found to be formed by individual Thai-Aus labourers as acquaintances as opposed to forming relationships as part of an organisation or institution. The social network knit is in a loose linking pattern as discussed above. The pattern appeared in the group of acquaintances or school friends or individuals that joined a social activity together.

The social networks of Thai-Aus labourers has expanded through the use "brokers" - the social network knit now depends on integration of benefits among members and building friendship among all levels of members. The sub-social networks of Thai-Aus labourers were clearly coordinated by a broker who coordinated in terms of benefits. This pattern was found in "Phan's" group (whose members were: "Dech", "Noi"," oil"," Wan", and" Sompop", before "Pook" entered after the network expanded), "Dech's "group (with "Noi”," Wat"," Sak", and" Oil(", "Thep's" group (with "Wan",“ Kaew”," Noi”, and" Sak(”, and "Chai's "and" Kluay's "group (comprising "Ped", "Song", "Leng", and "Wat", before "Breeze" joined after the network expansion). 
During the next stage, the social networks were expanded by the members who was not a "broker", resulting in 3 additional members that formed the Thai-Aus labourers thereafter totaling 18 members. However, the network had the same characteristics without higher density. The fact that a social network expanded through the members in general, not through a "broker" of each sub-network, demonstrates its obvious loose-knit characteristic. The model of the relationships in the Thai-Aus labourers' social network is shown in Figure 1 below.

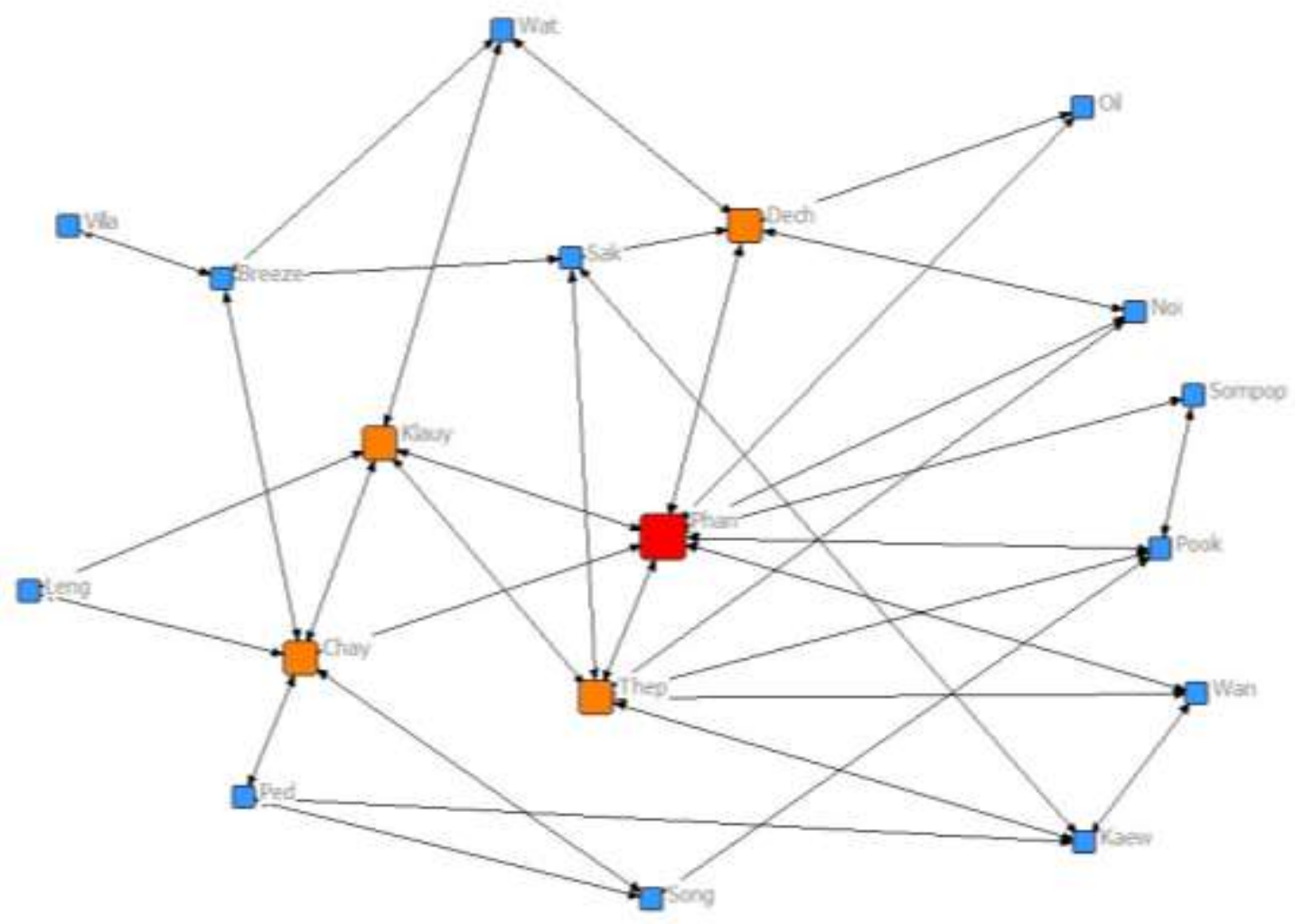

Figure 1 A model of relationships in the Thai-Aus labourers' social network

In Figure 1 it can be seen that the relationship of Thai-Aus labourers formed total connection of all members having "Phan", a Thai-Aus Labourer who had experiences from 3 entries to Australia as the center of the network. When considering the number of related pairs in the network, 9 pairs were found, demonstrating the highest density of relationships of this network. Thai-Aus labourers with whom "Phan" interacted had a member acting as the center of various sub-networks. The center member interacted with 5-6 Thai-Aus labourers and so a sub-network was formed. There were sub-networks of "Dech", "Thep", "Chai" and "Kluay". It was noted that each of the sub-networks had no relationship with one another, except the subnetwork of "Dech" and the sub-network of "Chai" and "Kluay". Other groups related only towards "Phan" who coordinated with the outside for the benefit of the members from the beginning. The popularity of "Phan" was confirmed by "Dech", who said:

..."It's good to be with Phan. He has a lot of experiences from coming here to study and work several times. He knows a lot of people, many work places. More importantly, he likes helping others..." (Interviewed on Skype on March 26, 2015)

The one-mode network was also another pattern of the Thai-Aus labourers' social networks. The relationships were measured at the level of pair of actors or between the actors and consideration was made pair by pair (Wasserman and Faust, 1999). This was found in both the sub-networks and major network, 
without any Thai-Aus labourer as the center on whom other members really depended. In other words, all network members had the choice to rely on more than one pair of relationships. This could be taken as the basis of social network knit which began from friendship and common experiences as the "people far from home" who left home to live in a distant land. "Wat", a young man from Nan stated:

..."I think we are on the same boat. From the outside, people back home in Thailand may think we're lucky because we study abroad. Some took a picture in front of the Opera House and posted it on the social media. A hundred friends in Thailand pressed 'like' ['Like' means appreciation via Facebook]. Do they really know how we really are?....We're lucky to have friends helping and supporting...." (Interviewed on We Chat on May 14, 2015).

\section{Relationships in the Social Networks of Thai-Aus Labourers}

After learning the social network formation and the characteristics of the social network of the Thai-Aus labourers as discussed above, I proceeded to analyse the relationships within their social networks based on the concept of Wasserman and Faust (1999) focusing on 4 major issues: the role of social network members, the basis of benefit exchange, the directional flow of relationships, and the frequency and duration of relationships, the details of which are described in detail below.

\subsection{The Roles of Members in the Social Networks}

The members of Thai-Aus labourers social networks both in the sub-networks and the major networks were found to take on bi-relationship roles, which were formed from the network knitting as friends and acquaintances rooted by personal connection and common experiences as well as social activity and job activity roles. The concentration of roles was obvious in the sub-network of Thai-Aus labourers with a broker at the center. In our case, these brokers were: "Phan", "Dech", "Thep", and "Cha" and "Kluay", all of whom performed their roles as the agents coordinating the employers in Sydney and assisting the other Thai-Aus labourers in their personal affairs and jobs. Nevertheless, the broker of the Thai-Aus labourers generally behaves as an ordinary member, not an outstanding person in the group. This is a common characteristic of Thai people who do not normally overact but respect those who "act rather than talk". Therefore, the broker of the Thai-Aus labourers are respected and accepted as the representative of the network by the members. In this regard, "Dech" told me that:

“...We are friends. No one is the head. But we respect our representative who takes responsibilities for us, coordinating with others and helping the newcomer or friends in trouble.....We are far away from home, and left home with a hope to have a better life." (Interviewed on July 25, 2015).

Additionally, the broker of the Thai-Aus labourers always opened a chance for the network members to perform their roles in social and job activities. For instance, a broker let a member organize a social activity of the group or assisted a member of another sub-network who was connected through the main network. Such demeanor of Thai-Aus labourer brokers enhanced the friendship and connections among members of the network, resulting in natural kinship interactions and respect towards one another. In addition, the network members received a chance to develop themselves from support of the broker to carry out various duties, which made each member feel valuable within the social network.

\subsection{Basis of Relationships based on the Exchanged Theory}

The roles of Thai-Aus labourers discussed in the previous section, especially the role in access to job opportunities depended on personal networks geared toward working networks in order to achieve the aim of working abroad. Even though the Thai-Aus labourers seemed to join the network to make new personal

Global J. Bus. Soc. Sci. Review 8 (3) $144-152$ (2020) 
relationships, it was also to obtain some benefit for themselves. This was because access to a job besides the one organized through the study abroad agent (the case selecting requirement of a part-time job), is based on assistance and coordination with Thai student friends or other Thai-Aus labourers. Therefore, a Thai-Aus labourer has to create a relationship and build a social network to identify job opportunities, as confirmed by "Dech":

“..The fact is...we have to accept that we need to depend on one another. No one is generous enough to pay for others. Each has to struggle in one way or another. There are some who may lend money to another, but it's just lending not giving...We all care for others' feeling, for we don't want the group to break apart. When there's a job, we can help out...." (Interviewed on July 25, 2015).

Such relationship was evident in the sub-networks where coordination was based on benefits, and which had the Thai-Aus labourer brokers like" Phan", "Dech"," Thep", and" Chai "and "Kluay" as the key members. The benefit exchange could be in the form of information such as employment opportunities, job contracting in a group, exchange of work shifts and in the form of money, getting-together for group activities, or articles. All of these were associated with the assumption of the Exchange Theory, which states that mutual action between individuals is done based on response, judged by reward and punishment or satisfactory and unsatisfactory. This means exchange of action between each other. It is also considered from receiving the greatest satisfaction (profits) after an action (investment), and is thought of as the action or reward from the other that makes the actor greatly satisfied (Ritzer, 1992; Chamaratana et. al., 2010).

It can also be said that the Thai-Aus labourers joined into a network in order to retain personal relationships and gave benefits to Thai-Aus labourer friends because they expected benefits from the ThaiAus labourer friends in return so that they could achieve the goals of their work.

\subsection{Directional Flow of Relationships}

When considering the context of Thai-Aus labourers who had exchanged activities and benefits between each other, we found the patterns of receiving benefits both equal and unequal. For instance, Thai-Aus labourers might pay back their friends by exchanging equivalent working hours, which is considered Balance Reciprocity. On the contrary, a Thai-Aus labourer might recompense a broker friend who substituted the job by sharing the wages according to the hours substituted. However, when this labourer replaced the broker at a job, he was paid back by being treated for a meal. The recompensing values, as can be seen, were not equal which is referred to as negative reciprocity. The values of reciprocity, when measured in terms of perception by the pair, were in fact more important than the amount of compensation. For this case, "Phan" confirmed the context of directional flow of such relationship as follows:

“...It's quite often that I swapped my shift with younger members. Sometimes, we even swapped the job contracted through 'Thep' or 'Kluay'. They recompensed by finding me another job... mostly contracted jobs with similar wages. For example, I found a member a job that paid 300 ASD, he then found me a job that paid 300-350 ASD..." (Interviewed conducted with "Phan" on July 26, 2015).

In addition, the system of values in the negative benefit exchange also involves satisfaction in the exchange in which the Thai-Aus labourer as a giver was willing to direct the relationship flow towards the exchange partner. This, in fact, depended on the personal ties of both and the power relationship of the exchange pair. An example can be given in the case of the Thai-Aus labourer broker, "Phan" who was clearly considered as the 'Broker of Brokers' in his social network even though he acted as a friend to all members. Since "Phan" was respected by all members, he would be assisted by a member at any time he wanted without agreement for compensation. In general, his exchange pair received assistance from him first, usually for personal reasons or personal satisfaction. 


\subsection{Frequency and Duration of Relationships}

Frequency and duration of relationships are the factors leading to the quality of a complex relationship. Likewise, frequency of relationship results from complex relationships. Ties and mutual influences in terms of bahaviours are the function of frequency of meetings and the duration of relationships. A person having frequent and long-term relationships with another person will have the influence on the manners towards each other owing to a high degree of ties. However, frequency of relationships alone is not enough to predict interpersonal relationships or behaviours (Wasserman \& Faust, 1999). This is common among Thai-Aus labourers who, even though they may work within the same company or the same team with another ThaiAus labourer, they do not necessarily have an influence over the behaviors of the other. In this study, one Thai-Aus labourer fell within this category; he was closer and more tied to another Thai-Aus labourer who used to work with him but subsequently moved, or a Thai-Aus labourer who used to study with him but had since returned to Thailand. Thus, it could be said that duration of relationships of Thai-Aus labourers influences the degree of ties and behaviours more than frequency of meetings.

For some Thai-Aus labourers, even though they maintained relationships with other Thai-Aus labourers for a long time, especially those coming from the same school in Thailand, their relationships with those people were not strong. This may be because when they received new experiences and met more people in their lives, their relationships were no longer prioritised. An example can be seen from "Kaew", who talked about "Thep", her friend from childhood:

"I've known 'Thep' since we were children. We also came to Sydney at nearly the same time. I helped him in his job once or twice, but I think it was tiring. The job required carrying loads of things. It was too hard for me. I prefer to work in a restaurant.... Now we meet each other sometimes. I'm not a close friend of anyone, for my study is hard. And I also work. That's why I don't hang out with anyone....." (Interviewed by Skype on September 7, 2015).

\section{Discussion, Conclusion and Implications}

From the above, it can be concluded that s networks' knit depends on coordination of benefits among the members and the creation of friendships at all levels. This results in sub-networks with a broker who coordinated the members for benefits. This research demonstrates that the formation of social networks among Thai-Aus labourers is a horizontal extension only, based on introduction via the broker and the members of sub-networks.

The extension of these social networks was the consequence of the strength of the "brokers", reflecting flexibility of the social network of Thai-Aus labourers that did not need "brokers" only. This confirms that the ties among Thai-Aus labourers are not intense because the connections were more of an "acquaintance" only. Therefore, the image of Thai-Aus labourers' social networks was still loose. This is consistent with a study by Ayuwat and Chamaratana (2013), which concludes that the network of brokers and brokers who sent Thai labourers abroad was loose and informal. However, one thing that significantly differed from this study is that the Thai-Aus labourers' network was not based on benefit exchange only the broker's network and labour network brokers. Instead, they use their 'heart' and 'friendship' in the exchange to maintain stability within the network. The knit and ties between each of the Thai-Aus labourers were, in general, in the form of friendly care, assistance in times of trouble, and 'cooperation' to work in a team for remuneration or wages so that they could live overseas.

The findings of this study are consistent with a similar study by Shah and Menon (1999), which examined working migration of labourers from Bangladesh, India, Pakistan, and Sri Lanka to Kuwait. More than one third of the labourers migrated to work in Kuwait via the social networks of nationals of their own country that temporarily formed a small group of personal relationships. The results of this study are also consistent with the findings of a study by Curran and Rivero-Fuentes (2003), which examined the network of Mexican 
migrants working in the United States via the social network, especially of relatives and close friends instead of through formal social networks.

The directional flow of relationships among Thai-Aus labourers comprised both receiving and giving of benefits between a pair of Thai-Aus labourers, resulting in balance reciprocity and negative reciprocity. These two exchanges were based on personal reasons or personal satisfaction. The exchange process was typically managed by a "broker" in order to retain the relationships among the members of the network. The duration of relationships of Thai-Aus labourers in the social network did not influence the degree of the relationships. The personal relationships of the Thai-Aus labourers in the network was more important. These findings are consistent with the assumption of the social network concept which indicates that the knit of people in the social network reflects the degree of network density. If a person is known by a lot of people or relates to a lot of people, that person has a network with a dense knit. This is in contrast with the case of a person known by few people who has a network with a loose knit pattern (Wasserman \& Faust, 1999).

However, when considering the context of the social network of Thai-Aus labourers, it was found that a person with a loosely knit relationship like "Sompop", Oil”, “Wat”,"Leng”, "Song”, and" Ped” did not feel left out or fear being cut off from the social network. They instead tried to keep the relationships and remain in the social network for employment and living overseas. This is consistent with the conclusions made by O'Connor (2013), which indicate that before job seekers can become employed with the social networks, contacts must first be able and willing to share their social resources. Little is known about the factors that affect their ability and willingness to do this. That study also found that they typically have access to resources and help job seekers by sharing them.

In addition, on the basis of perception and decision for mutual exchange, the Thai-Aus labourer brokers generally led the Thai-Aus labourers to exchange benefits, which could be in the form of information and suggestions, assets, money, entertaining activities, or a token of appreciation. This finding correlated to the assumption of the Exchange Theory (Ritzer, 1992; Chamaratana et. al., 2010). In other words, the Thai-Aus labourers formed a network to retain personal relationships as well as providing benefits to the Thai-Aus labourer friends with the expectation that they would also receive benefits from the friends and achieve their goal of working abroad. This is consistent with the conclusions made by Boonmak (2011), which indicates that the network of migrant labourers in Malaysia was principally formed on the basis of benefit exchange. However, in some cases, we found that they have a kinship relationship as the normal Thai culture that they can develop their relationship based on brotherhood. This is consistent with the study by Verdery, Entwisle, Faust and Rindfuss (2012), which concludes that close kin are more likely to co-reside, a fact which drives much of the relationship between kin and dwelling unit proximity within Thai villages.

In conclusion, the relationships within the social networks of the Thai-Aus labourers were complex, although they often shared the same goal. The relationships were principally based on benefit exchange even though personal relationships appeared on the surface. The directional flow of the relationships among ThaiAus labourers were found to be based on giving benefit and receiving benefit between a pair, resulting in both balance reciprocity and negative reciprocity. Both patterns depend mainly on personal reasons or personal satisfaction in order to maintain relationships among the members of the social network. As for the duration of relationships among Thai-Aus labourers, it was found that the duration did not affect the relationships, because they depended more on personal cases.

This research has some limitations. First, the target of study is focused only in Sydney, Australia. Future research should examine other locations where Thai students are known to reside to obtain more comprehensive results.

Based on the results of this study, it is recommended that the Ministry of Labour and Ministry of Foreign Affairs of Thailand should strictly observe the operations of the agencies that locate academic institutions for Thai migrants with an ulterior motive i.e. those who intend not to study but to work full time in their destination country. Further, the Thai Embassy in Australia should to assist the Thai-Aus networks to enable them to efficiently assist themselves. 


\section{Acknowledgements}

This research was granted the scholarship for research and presentation of research work by the Thailand Research Fund (TRF).

\section{References}

Ayuwat, D., \& Chamaratana, T. (2014). The role of labour broker networks in setting the price of working abroad for thai migrant workers. Asia-Pacific Population Journal, 28(2), 51-68. https://doi.org/10.18356/2702b8d0-en

Boissevain, J. (1974). Friends of friends: Networks, manipulators and coalitions. St. Martin's Press. https://www.jstor.org/stable/2778125

Boonmak, Sutthiporn. (2011). The Roles of Migration Network of Thai-Malaya Labourers in Malaysia's Tomyam Restaurant. Humanities and Social Sciences Journal, Thaksin University, 8(3), January - April, 2011: pp. 24-40.

Chanarnupap ,Sansanee. (2013). From 'Overseas Student' to 'Immigrant': Thai Skilled Migration to Australia.

$\begin{array}{llllll}\text { Kasetsart Journal } & \text { (Social } & \text { Science), } & 34(2013): & 514 & -\end{array}$

http://kasetsartjournal.ku.ac.th/kuj_files/2013/A1311251448171562.pdf

Thanapruek Chamarat. (2017). Child Placements: Role of Social Networks on the Livelihood of Thai Student Workers in Australia. Journal of Liberal Arts Prince of Songkla University, 9 (2), 260. -282. https://so03.tcithaijo.org/index.php/journal-la/article/view/107741

Chamaratana, T., Ayuwat, D., Knippenberg, L., \& De Jong, E. (2010). Connecting the Disconnected: Background, Practices and Motives of Labour Brokers in Isan, Thailand-an Explorative Study. International Journal of Interdisciplinary Social Sciences, 5(5). https://doi.org/10.18848/1833-1882/cgp/v05i05/51710

Creswell, J. W., \& Clark, V. L. P. (2017). Designing and conducting mixed methods research. Sage publications. https://doi.org/10.1177/1094428108318066

Curran, S. R., \& Rivero-Fuentes, E. (2003). Engendering migrant networks: The case of Mexican migration. Demography, 40(2), 289-307. https://link.springer.com/article/10.1353/dem.2003.0011

Wouter, D. N., Andrej, M., \& Vladimir, B. (2005). Exploratory social network analysis with Pajek. New York. https://assets.cambridge.org/97811070/02388/frontmatter/9781107002388_frontmatter.pdf

Giulietti, C., Schluter, C., \& Wahba, J. (2011). Migrants and social networks: Old ideas, lasting myths and new

findings. IZA Discussion

http://conference.iza.org/conference_files/Transatlantic2011/giulietti_c5931.pdf

Kilduff, M., \& Tsai, W. (2003). Social networks and organizations. Sage.

O'Connor, L. T. (2013). Ask and you shall receive: Social network contacts' provision of help during the job search. Social Networks, 35(4), 593-603. https://doi.org/10.1016/j.socnet.2013.07.005

Office of Overseas Thai Labourers. (2017). "Statistics of Thai Overseas Labourers". Retrieved March 11, 2017 from: http://www.overseas.doe.go.th.

Ritzer, G., \& Stepnisky, J. (2020). Classical sociological theory. SAGE Publications, Incorporated.

Shah, N. M., \& Menon, I. (1999). Chain migration through the social network: experience of labour migrants in Kuwait. International migration, 37(2), 361-382. https://doi.org/10.1111/1468-2435.00076

Srisantisuk, Somsak. (2007). Social Science Research Methodology: Methods for Quantitative and Qualitative Study. 7th ed. Khon Kaen: Faculty of Humanities and Social Sciences, Khon Kaen University. https://www.researchgate.net/scientific-contributions/2113304312-Sekson-Yongvanit

Verdery, A. M., Entwisle, B., Faust, K., \& Rindfuss, R. R. (2012). Social and spatial networks: Kinship distance and dwelling unit proximity in rural Thailand. Social networks, 34(1), 112-127. https://doi.org/10.1016/j.socnet.2011.04.003 Wasserman, S., \& Faust, K. (1994). Social network analysis: Methods and applications (Vol. 8). Cambridge university press. 